\title{
LABORATORY STUDY ON INFLUENCE OF AIR DUCT THROTTLING ON EXHAUST GAS COMPOSITION IN MARINE FOUR-STROKE DIESEL ENGINE
}

\author{
Jerzy Kowalski \\ Gdynia Maritime University \\ Department of Engineering Sciences \\ Morska Street 81-87, 81-225 Gdynia, Poland \\ tel.: +4858 6901434, fax: +48586901399 \\ e-mail:jerzy95@am.gdynia.pl
}

\begin{abstract}
Presented paper shows results of laboratory tests on the relationship between the throttling of a cross area of an air intake duct and the composition of exhaust gas from the marine engine. The object of research is a laboratory four-stroke diesel engine, worked with a load from $50 \mathrm{~kW}$ to $250 \mathrm{~kW}$ at a constant speed. During the laboratory, tests over 50 parameters were measured of the engine with technical condition recognized as a "working properly" and with a simulated the air intake duct throttling. The simulation consisted of inserting the throttling flanges to the air intake duct before compressor, limiting duct cross-sectional area by $20 \%$ and $60 \%$ respectively. The results of laboratory research confirm that the effect of the air intake duct throttling on the engine thermodynamic parameters is clearly visible only at considerable throttling. In the case of measuring the composition of exhaust gas, both mole fractions and emissions of gaseous components markedly affected even at low throttling. For example, 20\% throttling of the cross section of the air intake duct increase the mole fraction of carbon monoxide in exhaust gas almost $44 \%$ during working the engine with load equal to $250 \mathrm{~kW}$, and only $10 \%$ of the temperature after air cooler. Keep in mind that the temperature after air cooler was an engine parameter, which undergoes the greatest change during the simulation of that malfunction. The conclusion is that the results of measurements of the composition of exhaust gas may contain valuable diagnostic information about the technical condition of the air delivery to the engine system.
\end{abstract}

Keywords: marine diesel engine, exhaust gas composition, toxic emission, laboratory investigation, air duct throttling

\section{Introduction}

A design of a marine diesel engine should ensure the reliable and economic operation with fulfilment of environmental standards. Necessary for this purpose is the preparation and delivery to the engine cylinders homogeneous combustible mixture in the whole engine load. Operation of the engine causes, in time, the deterioration of its work efficiency, due to various kinds of disability. These failures result in deterioration of the combustion process in engine cylinders. The effect of this situation is increased fuel consumption. Due to not effective combustion process of mixture in cylinders, the composition of exhaust gas is changed [1-5].

The mixture burned in cylinders of the diesel engine is made up of the evaporated fuel dose, air supplied through the charging system and some part of combustion products. The composition of the combusted mixture changes with rotation of the crankshaft, the engine load and speed, and the technical condition of engine components and systems. Solid particles contained in the air supplied to the engine can cause damage to the compressor and other components of the engine charging system. Therefore are commonly used air filters that are choking in time. This causes the air intake duct throttling and changes in the parameters of the combustion process. The effect of these may be change composition of exhaust gas.

The paper presents results of experimental studies on the effects of throttling the cross area of the engine air intake duct on the composition of exhaust gas. 


\section{Laboratory stand}

The object of study is 3-cylinder, four-stroke, laboratory engine type AL25/30 Cegielski-Sulzer manufacturer, installed in the Laboratory of Internal Combustion Engines in Gdynia Maritime University. This engine is loaded with generator, electrically connected to the water resistance, and supercharged by VTR 160 Brown-Boveri turbocharger. During tests, the engine was fuelled by diesel oil and worked at a constant speed, equal to $750 \mathrm{rpm}$. There were measured 56 parameters of the laboratory stand including the engine load and speed, parameters of the turbocharger, systems of cooling, fuelling, lubricating, and air exchange. The composition of exhaust gas was also recorded using electrochemical gas analyser. Pressure, temperature and humidity of air were recorded by laboratory equipment also. All mentioned results were recorded with a sampling time of 1 second. Injection pressures and pressures of combustion in all cylinders of the engine were also collected. Scheme of the laboratory stand is presented in Fig. 1 and the engine parameters in Tab. 1.



Fig.1. The laboratory stand scheme. 1 - generator, 2 -water resistance, 3 - gas analyser, 4 - computer, 5 - A/C converter, 6-combustion pressure indicator, 7 -injection pressure indicator, 8 - exhaust duct

Tab. 1. Parameters of the Al25/30 engine

\begin{tabular}{|l|l|l|}
\hline \multicolumn{1}{|c|}{ Parameter } & \multicolumn{1}{c|}{ Value } & \multicolumn{1}{c|}{ Unit } \\
\hline Max Power & 250 & $\mathrm{~kW}$ \\
\hline Rotational speed & 750 & $\mathrm{rpm}$ \\
\hline Bore & 250 & $\mathrm{~mm}$ \\
\hline Stroke & 300 & $\mathrm{~mm}$ \\
\hline Compression ratio & 12.7 & - \\
\hline
\end{tabular}

During each start of observation, the engine was loaded to a value equal to $250 \mathrm{~kW}$, and after stabilizing temperature of exhaust gas after the turbine, engine operating parameters were recorded for 3 to 5 minutes. The next measurements were made with smaller loads at $10 \mathrm{~kW}$ up to load 
equal $50 \mathrm{~kW}$. The engine did not work with a load of $190 \mathrm{~kW}$ due to resonance vibrations. The presented results are averages for individual engine loads and observations.
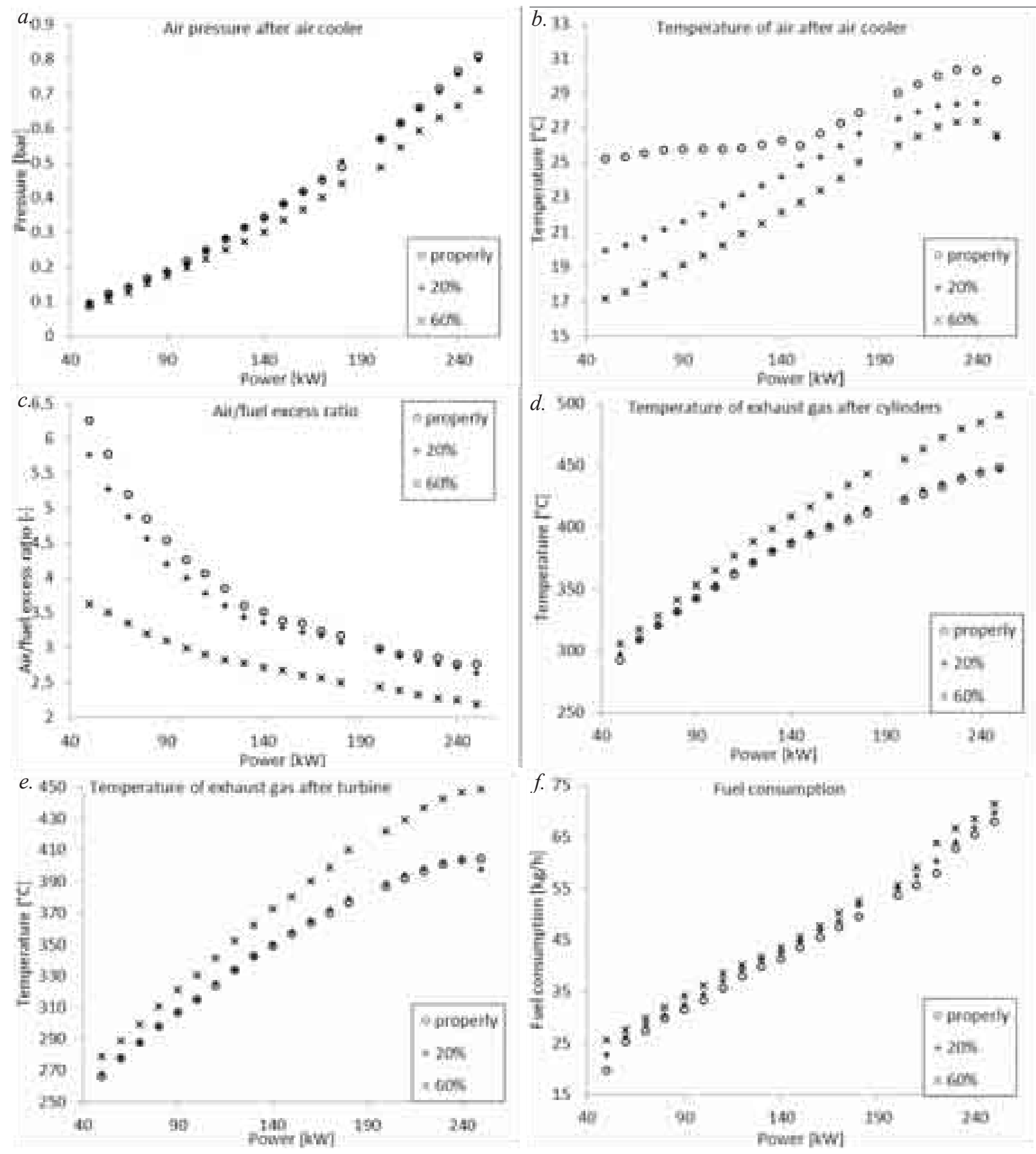

Fig. 2. Thermodynamic changes during throttling the air intake duct: a. Air pressure after the air cooler, $b$. Air temperature after the air cooler, c. Air-fuel excess ratio, d. Exhaust gas temperature after cylinders, e. Exhaust gas temperature after the turbine, $f$. Fuel consumption

\section{Results and discussion}

Aim of the research is determination the relationship between the throttling of the cross area of the air intake duct and the composition of diesel engine exhaust gas. Four observations were made with the laboratory engine running with the technical condition recognized as "working properly" and at three observations with simulation of the throttling of the air intake duct of the engine. 




Fig. 3. Exhaust gas composition: a. Oxygen mole fraction in exhaust gas, $b$. Carbon dioxide mole fraction in exhaust gas, c. Carbon dioxide emission from the engine, $d$. Carbon oxide mole fraction in exhaust gas, e. Exhaust gas flow rate, $f$. Carbon oxide emission from the engine

The simulation consisted of inserting throttling flanges to the air intake duct before the compressor, limiting duct cross-sectional area by $20 \%$ and $60 \%$ respectively compared to the "working properly" engine.

\subsection{Thermodynamic changes}

Throttling of the cross area of the air intake duct reduces pressure of charging air and reduces its temperature. Fig. $2 \mathrm{a}$ and Fig. $2 \mathrm{~b}$ shows the decreasing of temperature and pressure of air, measured in a point after the air cooler. According to presented results the changing of air pressure is clearly visible only for $60 \%$ throttling of the cross area of the air intake duct. The mentioned 
pressures decrease for this condition by $10-12 \%$ in all considered loads of the engine. The decreasing of air temperature, presented in Fig. $2 \mathrm{~b}$ is the best indicator of the throttling of the intake air duct among considered thermodynamic parameters of the engine. This temperature decreases average by $5 \%$ to $20 \%$ for the $20 \%$ throttling of the cross area of the air intake duct, and by $10 \%$ to $30 \%$ for the $60 \%$ throttling of the cross area of the air intake duct. The consequence of this is to reduce the amount of air supplied to engine cylinders. Fig. 2c shows changing of calculated air-fuel excess ratio for all mentioned malfunctions and loads of the engine. The airfuel excess ratio was calculated according to the following dependence:

$$
\lambda=\frac{21 \% O_{2}}{21 \% O_{2}-U_{O 2}},
$$

where:

$\lambda \quad-$ air-fuel excess ratio [-],

$21 \% \mathrm{O}_{2}-$ mole fraction of oxygen in air,

$U_{O 2} \quad-$ mole fraction of oxygen in exhaust gas.

Similarly, to earlier presented results the air-fuel excess ratio decrease average only by $4-5 \%$ for the $20 \%$ throttling of the air intake duct. The air intake duct throttling by $60 \%$ causes decreasing of the air-fuel excess ratio average by $25 \%$. The effect of throttling is more apparent in high load conditions. Decreasing among of air delivered to engine cylinders causes the combustion process of a mixture consisting of more fuel. This situation promotes extension of the combustion process in time. The effect of this is increasing the exhaust temperature after cylinders and temperature of exhaust gas after the turbine. Fig. $2 d$ shows temperature of exhaust gases measured after cylinders for all considered malfunctions and loads of the engine. There are mean temperatures for all cylinders. According to presented results, only high throttling of the air intake duct causes results in increasing of temperature after cylinders. Fig. 2e shows temperature of exhaust gas after the turbine. The results are similar to results of temperature after cylinders. Only high throttling of the air intake duct causes that there are differences more apparent in relation to results, taken from the "working properly" engine. The observed differences amounted from $4 \%$ for low loads to $11 \%$ for the load equal $250 \mathrm{~kW}$.

Abnormalities in the combustion process causes growth of fuel consumption. Fig. 2f shows measured fuel consumption for all considered states of the engine. Increasing the throttling of the cross area of the air intake duct causes increasing of the fuel consumption. The differences between the "working properly" engine and malfunctioned not exceed $5 \%$ for the $20 \%$ throttling and $10 \%$ for the $60 \%$ throttling. It should be noted that the fuel consumption is very important parameter from an economic point of view but in a practical application (e.g. on board use) very difficult to measure.

Assuming the measuring thermodynamic parameters are not enough to indicate abnormal throttling of the air intake duct. Only values of air temperature after the air cooler decrease apparent with the $20 \%$ throttling. It should be noted that indicated differences of measured parameters might not be detected during on-board maintenance. The reason of this is impact on air temperature a number of factors including condition of all elements of the air delivery system.

\subsection{Exhaust gas composition changes}

Throttled the cross area of the air intake duct reduces amount of air delivered to cylinders of the engine. It is clearly visible in the composition of exhaust gas for both considered malfunctions. Fig. 3a shows the dependence between load of the engine and a concentration of oxygen in exhaust gas. According to presented results the throttling of the cross area of the air intake duct causes apparent decreasing of oxygen content in exhaust gas in all considered loads of the laboratory engine. The $20 \%$ throttling decreases of oxygen mole fraction in exhaust gas average by $2 \%$, and the $60 \%$ throttling by $13 \%$ respectively. Presented relative decreases are stable for all considered loads of the engine. 

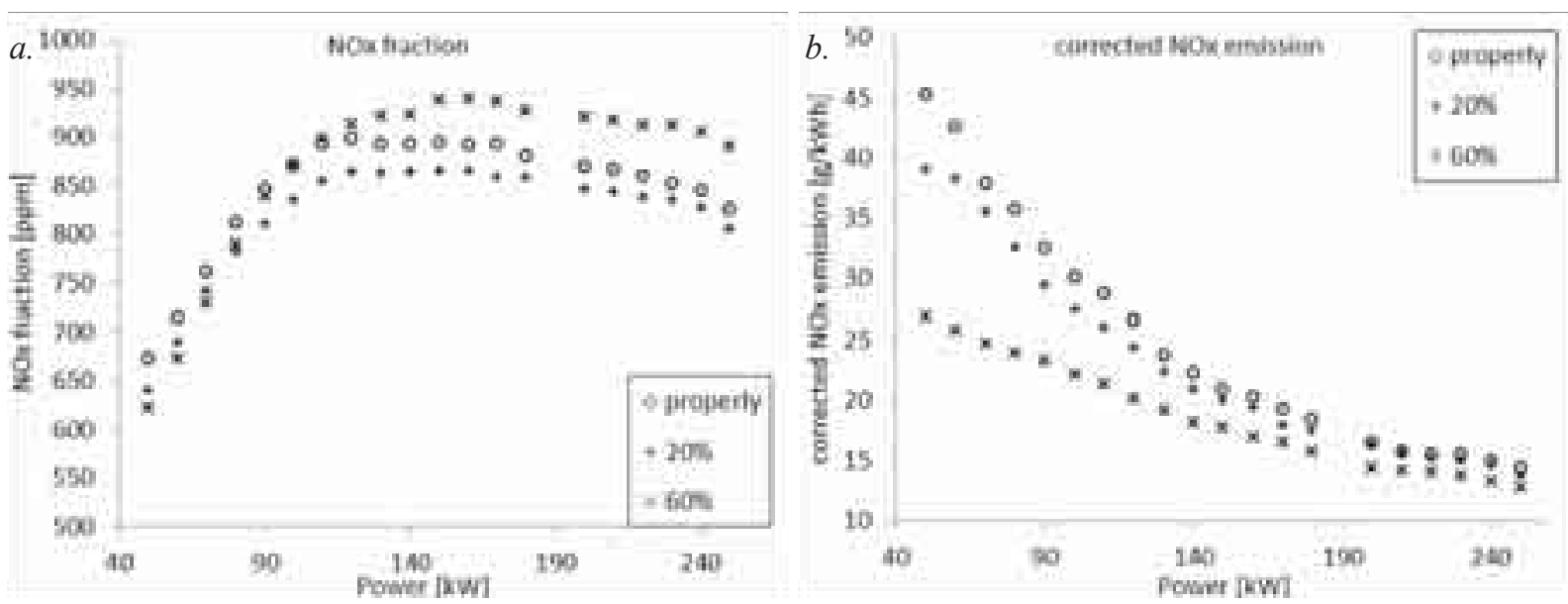

Fig.4. Exhaust gas composition: a. Nitric oxides mole fraction in the exhaust gas, $b$. Corrected emission of the nitric oxides from the engine

The effect of increasing of the fuel consumption is visible in Fig. $3 \mathrm{~b}$ and Fig. 3c. Increasing the dose of fuel delivered to the combustion process increases carbon monoxide in exhaust gas. The reason of this fact is consistence of carbon in fuel. Fig. 3.b presents a mole fraction of carbon dioxide in exhaust gas in all considered malfunctions and loads of the engine. Increasing of the engine load and the throttling of the cross area of the air intake duct increases the mole fraction of carbon dioxide. Fig. 3c presents the calculated emission of $\mathrm{CO} 2$ from engine. Levels of emission all mentioned chemical compounds of exhaust gas are calculated according to ISO 8178 rules [6]. According to dependences presented in Fig. 3c the air duct throttling decrease the level of $\mathrm{CO} 2$ emission. The $20 \%$ throttling of the cross area of the air intake duct decreases level of $\mathrm{CO} 2$ emission by $1 \%$ to $11 \%$ (higher differences for lower load of the engine) and decreases the mole fraction of $\mathrm{CO} 2$ by $1 \%$ (constantly for all loads of the engine). More appearance effects are in higher throttling conditions. The $60 \%$ throttling of the cross area of the air intake duct decreases level of $\mathrm{CO} 2$ emission by $8 \%$ to $36 \%$ (higher differences for lower load of the engine) and increases the mole fraction of $\mathrm{CO} 2$ by $0 \%$ to $10 \%$ (higher differences for higher loads of the engine). In explanation of this phenomenon are helpful the results presented in Fig. 3d and Fig. 3f. Mentioned dependences show mole fractions and calculated emissions of carbon monoxide. Increasing the throttling of the air intake duct deteriorates combustion conditions in engine cylinders. Effect of this is increasing the fuel consumption and increasing not complete burned fractions in exhaust gas. These not complete burned fractions are carbon monoxide and not measured in this test soot, consisted of not burned carbon. It means that a sum of emitted carbon in exhaust gas increase according to increase the fuel consumption but level of $\mathrm{CO} 2$ emission may decrease.

Calculation of the emission level needs information about flow rate of exhaust gas. The flow rates are calculated on the basis of the carbon balance according to ISO 8178 rules. Effects of calculation are presented in Fig.3e. According to presented dependences, the throttling of the air intake duct decrease the flow rate of exhaust gas and increasing the load of the engine increase mentioned flow. This result is expected by author because of qualitatively compliance with other publications [7].

Figure $4 \mathrm{a}$ presents dependences of the engine load on the mole fraction of nitric oxides in exhaust gas. The mole fraction of nitric oxides is assumed as a sum of mole fractions both the nitric oxide and the nitric dioxide. According to presented dependences the $20 \%$ throttling of the cross area of the air intake duct decreases the nitric oxides mole fraction in exhaust gas average by $2 \%$ to $4 \%$. The $60 \%$ throttling of the cross area of the air intake duct also decrease the mole fraction of nitric oxides in exhaust gas but only in low loads of the engine. High loads cause increase of the nitric oxides mole fraction. Explanation of this phenomenon is a strong dependence between the quantity 
of flow rate of exhaust gas (depended on fuel consumption and air-fuel excess ratio) and the quantity of measured gas (the nitric oxides in this case). Comparison of nitric oxides mole fractions from Fig. $4 \mathrm{a}$ and air-fuel excess ratio from Fig. $2 \mathrm{c}$ shows that the $60 \%$ throttling in the low load condition of the engine decrease air-fuel excess ratio about $40 \%$ but in the high load condition only about $20 \%$. This is the reason for the more applicable parameter is the emission than the mole fraction.

Figure $4 \mathrm{~b}$ shows dependences between a corrected nitric oxides emission and the load of the engine and the throttling of the cross area of the air intake duct. The nitric oxides emission depends not only on parameters of the working engine but also on parameters of surrounded the engine air. Mentioned parameters are temperature, pressure and humidity of air. According to ISO 8178 rules standard parameters of air for the nitric oxides measuring are:

- pressure $-101.3 \mathrm{kPa}$,

- temperature $-25^{\circ} \mathrm{C}$,

- humidity $-10.71 \mathrm{~g}_{\mathrm{H} 2 \mathrm{O}} / \mathrm{kg}$ of air.

According to mentioned European standard, all emissions of nitric oxides from diesel engines measured in other air conditions must be corrected to standard parameters by using the correction formula. The dependencies from Fig. $4 \mathrm{~b}$ show that despite results presented in the Fig. 4a, increase the throttling of the cross area of the air intake duct reduces the emission level of nitric oxides for all considered loads of the engine. The reduction of the nitric oxides emission increases with decreasing of the engine load. For the $20 \%$ throttling the average reduction of the nitric oxides emission is from $2 \%$ for high load engine conditions to $13 \%$ for low load. The $60 \%$ throttling reduces the nitric oxides emission for $10 \%$ to $40 \%$ respectively.

Presented results show that in the formation of nitric oxides during the combustion process prevails Zeldovitch's mechanism, even at the maximum considered throttling of the air intake duct. It means that the throttling causes reduction of the oxygen quantity in engine cylinders, increase the time of the combustion but not increase temperature of the combustion in cylinders.

\section{Conclusions}

The paper presents results of laboratory tests carried out on a four-stroke diesel engine for marine applications. The study consisted in determining the impact of the cross area throttling of the air intake duct on engine operating parameters including the composition of exhaust gas. The obtained results allow concluding that the throttling of the cross area of the air intake duct by $20 \%$ causes significant impairment of the combustion process in engine cylinders. It shows a $5 \%$ increase in the fuel consumption and changes in the composition of exhaust gas. Unfortunately, these changes are not apparent in measured values of thermodynamic parameters of the engine. Only the cross area throttling of the air intake duct by $60 \%$ cause visible changes at both gas temperature and pressure behind the cooler. The study results show an increase of CO emission and decrease of the nitric oxides emission and the carbon dioxide emission along with the throttling the air intake duct. These changes are also noticeable for the $20 \%$ throttle.

The obtained results allow concluding that the composition of exhaust gas can give with its image important diagnostic signals about the technical condition of the engine air intake duct.

\section{Acknowledgments}

The project was supported by the National Science Centre in Poland, granted on the basis of decision No. DEC-2011/01/D/ST8/07142.

\section{References}

[1] Hillion, M., Chauvin, J., Petit, N., Control of highly diluted combustion in Diesel engines, Control Engineering Practice, Elsevier, Vol. 19, pp. 1274-1286, 2011. 
[2] Hountalas, D. T., Kouremenos, A. D., Development and application of a fully automatic troubleshooting method for large marine diesel engines, Applied Thermal Engineering, Elsevier, Vol. 19, pp. 299-324, 1999.

[3] Porteiro, J., Collazo, J., Patiño, D., Míguez, J. L., Diesel engine condition monitoring using a multi-net neural network system with nonintrusive sensors, Applied Thermal Engineering, Elsevier, Vol. 31, pp. 4097-4105, 2011.

[4] Asad, U., Zheng, M., Fast heat release characterization of a diesel engine, International Journal of Thermal Sciences, Elsevier Vol. 47, pp. 1688-1700, 2008.

[5] Hountalas, D. T., Prediction of marine diesel engine performance under fault conditions, Applied Thermal Engineering, Elsevier, Vol. 20, pp. 1753-1783, 2000.

[6] ISO 8178 - Reciprocating internal combustion engines.

[7] Heywood, J. B., Internal Combustion Engine Fundamentals, McGraw-Hill, 1988. 